\title{
Valor Nutritivo e Desempenho de Leitões Alimentados com Rações Contendo Silagem de Grãos Úmidos de Milho ${ }^{1}$
}

\section{Ricardo Pinto de Oliveira ${ }^{2}$, Antonio Claudio Furlan ${ }^{3}$, Ivan Moreira ${ }^{3}$, Alessandro Luís Fraga ${ }^{4}$, Alexandre Orio Bastos 5}

\begin{abstract}
RESUMO - Um ensaio de digestibilidade (experimento 1) foi conduzido para determinar os coeficientes de digestibilidade aparentes da matéria seca (CDMS), proteína bruta (CDPB), amido (CDAM) e energia bruta (CDEB) e o coeficiente de metabolização da energia bruta (CMEB) da silagem de grãos úmidos de milho (SGUM). Foram utilizados 12 suínos mestiços (Landrace, Large-White e Duroc) machos castrados, alojados em gaiolas de metabolismo, distribuídos em um delineamento experimental inteiramente casualizado. O método utilizado foi o da coleta total de fezes e urina. Os valores de matéria seca digestível (MSD), proteína digestível (PD), amido digestível (AD), energia digestível (ED) e energia metabolizável (EM), na matéria natural (60,18\% de MS), foram, respectivamente, 48,70; 3,77; 42,35\%; 2.389 e $2.327 \mathrm{kcal} / \mathrm{kg}$ de SGUM. O experimento 2 foi conduzido para avaliar o desempenho de leitões e a viabilidade econômica da utilização das rações com diferentes níveis de substituição do milho seco por SGUM. Foram utilizados 48 suínos mestiços (Landrace, Large White e Duroc), distribuídos em um delineamento inteiramente casualizado, com seis repetições e dois animais por unidade experimental. Os tratamentos consistiram de uma ração à base de milho e farelo de soja e outras três com 33, 66 e 100\% de substituição do milho seco por SGUM com base nos valores de energia digestível. Não houve efeito da inclusão de SGUM sobre o ganho de peso e o consumo de ração, porém ocorreu redução linear na conversão alimentar e no custo da ração por quilograma de peso vivo ganho. Os dados indicam que o milho seco pode ser totalmente substituído pela SGUM em rações para leitões em fase de creche, com melhora nos índices produtivos e econômicos.
\end{abstract}

Palavras-chave: alimento alternativo, custo ração, fase inicial, nutriente digestível, nutriente metabolizável

\section{Nutritive Value and Performance of Piglets Fed Rations Containing High Moisture Corn Silage}

\begin{abstract}
A digestibility assay was carried out to determine the dry matter apparent digestibility coefficients (DMDC), crude protein (CPDC), starch (SDC), gross energy (GEDC) and gross energy metabolization coefficient (GEMC) of high moisture corn silage (HMCS). Twelve crossbred (Landrace x Large-White x Duroc) castrated males were allotted to metabolism cages, in a completely randomized design. The total feces and urine collection method was used. The values of digestible dry matter (DDM), digestible protein (DP), digestible starch (DS), digestible energy (DE), and metabolizable energy (ME) of HMCS were 48.70, 3.77, 42.35\%, and 2,389 and 3,327 kcal/kg, respectively, based on natural matter $(60.18 \% \mathrm{DM})$. The experiment 2 was carried out to evaluate piglet performance and economic viability of diets with different substitution levels of dry yellow corn by HMCS. Forty-eight cross-breed (Landrace x Large-White x Duroc) piglets were used. The piglets were divided into four treatments in a completely randomized design, with six experimental units and two piglets per experimental unit. The treatments consisted of a basal corn-soybean meal diet and three diets with increasing dry yellow corn substitution by HMCS levels (33, 66 and 100\%), based on the digestible energy content of dry yellow corn and HMCS. There was no effect of increasing levels of HMCS on daily weight gain and daily feed intake. Linear reduction on feed conversion and diet cost per kilogram of weight gain was observed. Data indicate that dry corn can be completely replaced by HMCS on piglets diets, with improvement on performance and economic index.
\end{abstract}

Key Words: alternative feed, diet cost, digestible nutrient, initial phase, metabolizable nutrient

\section{Introdução}

O milho seco tem sido a principal fonte energética empregada na alimentação de animais monogástricos, sendo responsável pela maior parte da composição percentual das rações de suínos. Como a alimentação representa o item de maior custo na produção animal, há interesse contínuo na busca por alimentos alternativos que permitam minimizar os gastos com a alimentação e, conseqüentemente, reduzir o custo de produção do suíno.

\footnotetext{
1 Parte da dissertação do primeiro autor apresentada ao PPZ/DZO/UEM, Maringá, como um dos requisitos para a obtenção do título de mestre em Zootecnia.

2 Zootecnista, aluno do curso de Pós-Graduação em Zootecnia - UNESP - Botucatu. E.mail: rpoliveira@fca.unesp.br

3 Professores do Departamento de Zootecnia da UEM, Av. Colombo, 5790 - 87020-900, Maringá - PR. E.mail: acfurlan@uem.br; imoreira@uem.br

4 Médico Veterinário, aluno do curso de Pós-Graduação em Zootecnia - UNESP - Jaboticabal.

5 Zootecnista, aluno do curso de Pós-Graduação em Zootecnia - UEM - Maringá.
} 
O emprego do milho na forma de silagem de grãos úmidos em rações para suínos é uma alternativa para a produção de grãos na propriedade. Diversas vantagens em relação ao milho seco são apresentadas na literatura, dentre elas, antecipação da colheita, redução nas perdas quantitativas e qualitativas na fase pós-colheita, sistema de armazenamento mais simples e econômico, conservação do valor nutritivo por maior período de tempo, maior disponibilidade de nutrientes, menor incidência de diarréia em animais recém-desmamados e ausência de taxas e impostos, que incidem sobre o preço do milho seco que é adquirido no mercado formal.

A avaliação de alimentos alternativos torna-se importante para o conhecimento da digestibilidade de seus nutrientes para a formulação de rações. $O$ custo desse ingrediente, associado ao seu valor nutricional, será determinante no custo de produção do suíno.

Em relação ao milho seco, o milho submetido à fermentação anaeróbica propicia maior disponibilidade de energia (Lima et al., 1988) e de nitrogênio (Asche et al., 1986) para suínos. Além disso, é provável que a fermentação permita a gelatinização parcial do amido. Por outro lado, Engelke et al. (1984) concluíram que o milho estocado sob a forma de silagem de grãos úmidos de milho (SGUM) tem valor nutricional semelhante ao milho seco para suínos em fases de crescimento e terminação, quando comparados em mesma base de matéria seca.

Holmes et al. (1973) constataram que os coeficientes de digestibilidade da matéria seca, da energia e do nitrogênio da ração foram, em média, $4 \%$ maiores para suínos alimentados com silagem de grãos de milho comparado com aqueles que receberam dietas com milho seco. Esses autores concluem que a maior digestibilidade da MS ocorre em função da pré-digestão sofrida pelos grãos ensilados, da ação mais eficiente das enzimas digestivas nas partículas úmidas do milho e, também, à acidez da silagem, que retarda a permanência do alimento no estômago, com conseqüente maior ataque da amilase salivar.

Avaliando o desempenho de suínos, nas fases de crescimento e terminação, alimentados com rações contendo milho seco ou milho úmido ensilado, Engelke et al. (1984) não constataram diferenças na conversão alimentar. Por outro lado, Duduk (1988), utilizando as mesmas categorias de suínos, observou maior ganho de peso e melhor conversão alimentar, quando os animais receberam SGUM, comparados àqueles alimentados com milho seco. Trabalhando com suínos nas fases inicial, de crescimento e de terminação, Lopes et al. (1999a,b) obtiveram melhores índices de desempenho quando esses animais foram submetidos à dieta com substituição total do milho seco por SGUM.

A elaboração de ração na propriedade, a partir da SGUM, permite reduzir os custos de produção do suíno pelo barateamento da participação do milho na ração (Back, 2001). De acordo com Jobim et al. (2001), a redução dos custos de produção é muito importante, principalmente na suinocultura e bovinocultura leiteira, onde as margens de lucro são bastante pequenas e os preços estão sujeitos a grandes oscilações, em razão do mercado externo e dos preços do milho.

Embora em muitas suinoculturas, principalmente aquelas da região sul do país, seja adotada SGUM na alimentação de seus plantéis, considera-se escasso o número de trabalhos encontrados na literatura nacional a este respeito, o que justifica maior direcionamento dos trabalhos de pesquisa que avaliem a utilização desse produto para a alimentação de suínos.

O presente trabalho foi conduzido com o objetivo de avaliar, por meio de ensaio de digestibilidade e experimento de desempenho, o valor nutritivo da SGUM o seu efeito sobre o desempenho de leitões em fase de creche.

\section{Material e Métodos}

\section{Experimento I - Digestibilidade}

O experimento foi conduzido na sala de metabolismo do Setor de Suinocultura da Fazenda Experimental de Iguatemi (FEI), pertencente ao Centro de Ciências Agrárias da Universidade Estadual de Maringá (CCA/UEM) no período de 29 de agosto a 9 de setembro de 2000. Foram utilizados 12 suínos mestiços (Landrace X Large White X Duroc), machos, castrados, com $16,31 \pm 0,69 \mathrm{~kg}$ de peso vivo médio inicial.

Os animais foram alojados em gaiolas de metabolismo semelhantes às descritas por Pekas (1968). O período experimental teve duração de cinco dias de adaptação às gaiolas e às rações experimentais e cinco dias de coletas de fezes e urina. Foi utilizado o delineamento experimental inteiramente casualizado, com seis repetições, sendo a unidade experimental constituída por um suíno.

A variedade de milho (Zea mays) utilizada para a obtenção da SGUM foi a AG 9010, colhida em julho de 2000 na Fazenda Iguaçu, localizada no município 
de Mamborê - PR. A colheita foi realizada por colheitadeira mecânica. Os grãos foram triturados em moinho tipo martelo, utilizando peneira $10 \mathrm{~mm}$, e em seguida ensilados em tambores de polietileno com capacidade para 200 litros. Nessa ocasião, os grãos apresentavam teor de umidade de 39,82\%.

A ração-referência contendo $66 \%$ de milho seco, $30 \%$ de farelo de soja e $4 \%$ de núcleo foi formulada de acordo com a composição química e os valores energéticos dos ingredientes, segundo as tabelas da EMBRAPA (1991).

O alimento avaliado foi a SGUM (alimento teste), que substituiu, com base da matéria seca, $31 \%$ da ração-referência (RR), resultando em uma ração teste (RT), misturada diariamente. As rações foram fornecidas em porções iguais, às 8 e $14 \mathrm{~h}$. A quantidade total diária foi estabelecida de acordo com o consumo na fase de adaptação, com base no peso metabólico $\left(\mathrm{kg}^{0,75}\right)$ de cada unidade experimental.

Após cada refeição, foi fornecida água no comedouro, na proporção de $3,0 \mathrm{~mL} / \mathrm{g}$ de ração, calculada para cada unidade experimental, para evitar o excesso de consumo de água. Foi utilizado o método de coleta total de fezes, e a definição do início e final das coletas foi feita pela adição de marcador $\left(2 \%\right.$ de $\left.\mathrm{Fe}_{2} \mathrm{O}_{3}\right)$ às rações.

As fezes totais produzidas foram coletadas uma vez ao dia, acumuladas em sacos plásticos e armazenadas em congelador a $-18^{\circ} \mathrm{C}$. Posteriormente, foram homogeneizadas e uma amostra de $20 \%$ foi retirada, seca em estufa de ventilação forçada $\left(55^{\circ} \mathrm{C}\right)$ e moída para análise de matéria seca, amido, proteína bruta e energia bruta.

A urina foi coletada diariamente em baldes plásticos contendo $20 \mathrm{~mL}$ de $\mathrm{HCl} 1: 1$. Uma alíquota de $20 \%$ foi acumulada diariamente e congelada a $-18^{\circ} \mathrm{C}$, para determinação da energia bruta. Os teores de energia bruta das rações, da SGUM, das fezes e da urina foram determinados por meio de calorímetro adiabático (Parr Instrument Co., 1984).

As análises das amostras dos alimentos, das fezes e da urina foram realizadas no Laboratório de Nutrição Animal do Departamento de Zootecnia da Universidade Estadual de Maringá (LANA-DZO/ UEM), segundo os procedimentos descritos por Silva (1990). As determinações de amido dos alimentos e das fezes foram obtidas de acordo com o método enzimático proposto por Poore et al. (1989), adaptado por Pereira \& Rossi (1995). O valor de pH da SGUM foi determinado pelo método utilizado por Phillip \&
Fellner (1992). A análise de granulometria da silagem foi realizada seguindo a metodologia descrita por Zanotto \& Bellaver (1996).

Foram calculados os coeficientes de digestibilidade aparente da matéria seca (CDMS), da proteína bruta (CDPB), do amido (CDAM) e da energia bruta (CDEB) e o coeficiente de metabolização da energia bruta (CMEB) do alimento teste, determinados pelo método de coleta total de fezes e urina, conforme Moreira et al. (1994).

Os teores de matéria seca digestível (MSD), proteína digestível (PD), amido digestível (AD), energia digestível (ED) e energia metabolizável (EM) dos alimentos foram calculados utilizando a fórmula de Matterson et al. (1965).

\section{Experimento II - Desempenho}

O experimento foi conduzido na creche do Setor de Suinocultura, da FEI-CCA/UEM, no período de 15 de fevereiro a 15 de março de 2001.

Foram utilizados 48 leitões mestiços (Landrace, Large White e Duroc), com idade média inicial de 32 dias e $7,75 \pm 1,13 \mathrm{~kg}$ de peso vivo médio. Os animais permaneceram no experimento até uma idade média de 60 dias, quando atingiram $23,63 \pm 3,41 \mathrm{~kg}$ de peso vivo médio. Os animais foram alojados em creche de alvenaria, com cobertura de telhas de fibrocimento, disposta em quatro salas, cada uma com dez baias, divididas por um corredor central. As baias eram do tipo suspensas, contendo piso plástico e bebedouro tipo chupeta na parte posterior, e piso de concreto com comedouro de cinco bocas na parte frontal.

A SGUM utilizada neste experimento, avaliada no ensaio de digestibilidade, apresentou, na matéria natural, $60,18 \%$ de $\mathrm{MS}, 4,29 \%$ de $\mathrm{PB}, 2,81 \%$ de extrato etéreo, $1,40 \%$ de fibra bruta, $0,14 \%$ de fósforo total, $0,01 \%$ de cálcio e $2.389 \mathrm{kcal} \mathrm{ED} / \mathrm{kg}$. A composição em aminoácidos da SGUM foi calculada de acordo com o teor de proteína bruta $(4,29 \%)$ e a concentração de aminoácidos do milho seco apresentada nas tabelas da EMBRAPA (1991). A composição em nutrientes do milho, farelo de soja, calcário e fosfato bicálcico, utilizados nas rações foram obtidos das tabelas da EMBRAPA (1991).

Os tratamentos experimentais (Tabela 1) consistiram de quatro rações isoenergéticas, isocálcicas, isofosfóricas e isoaminoacídicas para lisina e metionina+cistina, contendo níveis crescentes de substituição $(0,33,66$ e 100\%) do milho seco por SGUM com base nos valores energéticos convertidos para $87,45 \%$ de matéria seca, atendendo, no mínimo, as 
Tabela 1 - Composição centesimal, composição química, valores energéticos, pH, diâmetro geométrico médio das partículas (DGM) e custo das rações experimentais

Table 1 - Centesimal composition, chemical composition, energy values, $\mathrm{pH}$ values, medium geometric diameter of particles and cost of the experimental diets

\begin{tabular}{|c|c|c|c|c|}
\hline \multirow[t]{2}{*}{$\begin{array}{l}\text { Variáveis } \\
\text { Variables }\end{array}$} & \multicolumn{4}{|c|}{$\begin{array}{l}\text { Níveis de substituição do milho seco comum por SGUM, } \% \\
\text { Substitution levels of normal dry corn for HMCS, \% }\end{array}$} \\
\hline & 0 & 33 & 66 & 100 \\
\hline Milho seco grão ${ }^{1}$ & 63,70 & 42,17 & 20,64 & - \\
\hline $\begin{array}{l}\text { SGUM }^{1} \\
H M C S\end{array}$ & - & 21,40 & 42,80 & 64,22 \\
\hline $\begin{array}{l}\text { Óleo de soja } \\
\text { Soybean oil }\end{array}$ & 0,89 & 0,97 & 1,05 & 1,12 \\
\hline $\begin{array}{l}\text { Açúcar } \\
\text { Sugar }\end{array}$ & 3,00 & 3,00 & 3,00 & 3,00 \\
\hline $\begin{array}{l}\text { Fosfato bicálcico } \\
\text { Dicalcium phosphate }\end{array}$ & 1,55 & 1,60 & 1,65 & 1,72 \\
\hline $\begin{array}{l}\text { Calcário } \\
\text { Limestone }\end{array}$ & 0,90 & 0,88 & 0,86 & 0,83 \\
\hline $\begin{array}{l}\text { Sal comum } \\
\text { Salt }\end{array}$ & 0,40 & 0,40 & 0,40 & 0,40 \\
\hline $\begin{array}{l}\text { Tylan S-100 } \\
\text { DL-Metionina }\end{array}$ & $\begin{array}{l}0,10 \\
0,05\end{array}$ & $\begin{array}{l}0,10 \\
0.07\end{array}$ & $\begin{array}{l}0,10 \\
0,09\end{array}$ & $\begin{array}{l}0,10 \\
0.12\end{array}$ \\
\hline$D L$-methionine & & & & \\
\hline $\begin{array}{l}\text { L-Lisina HCL } \\
\text { L-lysine } \mathrm{HCl}\end{array}$ & - & 0,02 & 0,04 & 0,09 \\
\hline $\begin{array}{l}\text { Suplemento vitamínico-mineral } \\
\text { Min. and vit. supplement } t^{2}\end{array}$ & 0,50 & 0,50 & 0,50 & 0,50 \\
\hline $\begin{array}{l}\text { Total } \\
\text { Valores calculados }\end{array}$ & 100 & 100 & 100 & 100 \\
\hline $\begin{array}{l}\text { Calculated values } \\
\text { Energia digestível, } \mathrm{kcal} / \mathrm{kg} \\
\text { Digestible energv, } \mathrm{kcal} / \mathrm{kg}\end{array}$ & 3.400 & 3.400 & 3.400 & 3.400 \\
\hline $\begin{array}{l}\text { Lisina total, \% } \\
\text { Total lysine, } \%\end{array}$ & 1,08 & 1,08 & 1,08 & 1,08 \\
\hline $\begin{array}{l}\text { Metionina+Cistina total, \% } \\
\text { Total methionine }+ \text { cystine, \% }\end{array}$ & 0,65 & 0,65 & 0,65 & 0,65 \\
\hline $\begin{array}{l}\text { Cálcio, \% } \\
\text { Calcium, \% }\end{array}$ & 0,84 & 0,84 & 0,84 & 0,84 \\
\hline $\begin{array}{l}\text { Fósforo total, } \% \\
\text { Total phosphorus, \% }\end{array}$ & 0,61 & 0,61 & 0,61 & 0,61 \\
\hline $\begin{array}{l}\text { Proteína bruta, } \% \\
\text { Crude protein, } \%\end{array}$ & 18,66 & 18,16 & 17,67 & 16,86 \\
\hline $\begin{array}{l}\mathrm{pH} \\
\mathrm{DGM}, \mu \mathrm{m}\end{array}$ & $\begin{array}{l}6,01 \\
661\end{array}$ & $\begin{array}{l}5,48 \\
743\end{array}$ & $\begin{array}{l}5,056 \\
789\end{array}$ & $\begin{array}{l}4,81 \\
928\end{array}$ \\
\hline $\begin{array}{l}M G D, \mu m \\
\text { Custo da ração, } \mathrm{R} \$ / \mathrm{kg} \\
\text { Diet cost, } R \$ / \mathrm{kg}\end{array}$ & 0,389 & 0,381 & 0,373 & 0,365 \\
\hline
\end{tabular}

${ }^{1}$ Valores em $87,45 \%$ de matéria seca.

2 Suplemento vitamínico-mineral. Conteúdo por kg de ração: Vit. A, 10.000 UI; Vit. $D_{3}, 2.000$ UI; Vit. E, 25 UI; Vit. $\mathrm{K}_{3}, 2 \mathrm{mg}$; Vit. $\mathrm{B}_{1}, 2 \mathrm{mg}$; Vit. $\mathrm{B}_{2}, 6 \mathrm{mg}$; Vit. $\mathrm{B}_{6}, 3 \mathrm{mg}$; Vit. $\mathrm{B}_{12}, 30 \mathrm{mcg}$; Ác. Nicotínico, $30 \mathrm{mg}$; Ác. Pantotênico, $12 \mathrm{mg}$; Biotina, 0,1 mg; Ác. Fólico, $1 \mathrm{mg}$; Selênio, 0,3 mg; Colina, $150 \mathrm{mg}$; Lisina, $1.170 \mathrm{mg}$; Promotor de crescimento, $50 \mathrm{mg}$; Antioxidante, $100 \mathrm{mg}$; lodo, $1,5 \mathrm{mg}$; Cobalto, $1 \mathrm{mg}$; Cobre, $175 \mathrm{mg}$; Zinco, $100 \mathrm{mg}$; Ferro, $100 \mathrm{mg}$; Manganês, $40 \mathrm{mg}$.

1 Values on $87.45 \%$ dry matter.

${ }^{2}$ Mineral-vitamin supplement. Nutritional levels per kg of diet: Vit. A, $10.000 \mathrm{UI}$; Vit. $D_{3}, 2.000 \mathrm{UI}$; Vit. E, $25 \mathrm{UI}$; Vit. $\mathrm{K}_{3}$, $2 \mathrm{mg}$; Vit. $B_{1}, 2 \mathrm{mg}$; Vit. $B_{2}, 6 \mathrm{mg}$; Vit. $B_{6}, 3 \mathrm{mg}$; Vit. $B_{12}$, $30 \mathrm{mcg}$; niacin, $30 \mathrm{mg}$; pantothenic acid, $12 \mathrm{mg}$; biotin, $0,1 \mathrm{mg}$; folacin, $1 \mathrm{mg}$; selenium, 0,3 mg; choline, $150 \mathrm{mg}$; lysine, $1.170 \mathrm{mg}$; growth promotor, $50 \mathrm{mg}$; antioxidant, $100 \mathrm{mg}$; iodine, $1,5 \mathrm{mg}$; cobalt, $1 \mathrm{mg}$; cooper, $175 \mathrm{mg}$; zinc, $100 \mathrm{mg}$; iron, $100 \mathrm{mg}$; manganese, $40 \mathrm{mg}$. 
exigências nutricionais propostas pelo NRC (1998) para leitões na respectiva faixa de peso.

Os ingredientes da ração, exceto a SGUM, foram previamente misturados. A SGUM foi incorporada diariamente às respectivas rações nos níveis de 33, 66 e $100 \%$ de substituição, originando os três tratamentos experimentais. As rações, pesadas diariamente, e a água foram oferecidas à vontade. Diariamente, as sobras das rações que continham SGUM eram recolhidas, pesadas e descartadas.

Os valores de $\mathrm{pH}$ das amostras das rações experimentais e da SGUM foram obtidos seguindo os procedimentos utilizados por Phillip \& Fellner (1992). As análises de granulometria da silagem e das rações experimentais foram realizadas de acordo com a metodologia proposta por Zanotto \& Bellaver (1996).

Os animais foram distribuídos em um delineamento inteiramente casualizado, com quatro tratamentos, seis repetições, com dois leitões por unidade experimental (um macho e uma fêmea). As pesagens dos animais foram realizadas no início, aos 14 e aos 28 dias do período experimental.

Os preços dos ingredientes utilizados na elaboração das rações experimentais foram coletados na região de Maringá - PR, no mês de novembro de 2001: milho seco, R \$ 0,19/kg; farelo de soja, R \$ 0,53/kg; óleo de soja, R\$ 1,26/kg; açúcar cristal, R\$ 0,75/kg; fosfato bicálcico, $\mathrm{R} \$ 0,88 / \mathrm{kg}$; calcário, $\mathrm{R} \$ 0,04 / \mathrm{kg}$; sal comum, R\$ 0,15/kg; Tylan S-100, R\$ 27,60/kg; DL-Metionina, R \$ 11,03/kg; L-Lisina HCl, R \$ 7,87/kg e suplemento vitamínico-mineral, $\mathrm{R} \$ 6,39 / \mathrm{kg}$. O preço da SGUM foi de R $\$ 0,13 / \mathrm{kg}$, quando ajustado para a mesma base de matéria seca do milho seco $(87,45 \%)$. Essa estimativa ocorreu de acordo com valores do custo de produção apresentados por Jobim et al. (2001), que levou em consideração os custos de um sistema terceirizado, da lavoura em pé, da colheita, do transporte, da trituração e da compactação da SGUM, com produtividade média de $8.300 \mathrm{~kg} / \mathrm{ha}$, durante o período de três anos (1995 a 1997).

Para verificar a viabilidade econômica da substituição do milho seco pela SGUM nas rações, foi determinado inicialmente o custo de ração por quilograma de peso vivo ganho $(\mathrm{Y} i)$, segundo Bellaver et al. (1985).

$$
\mathrm{Y} i=\frac{\mathrm{Q} i \mathrm{X} \mathrm{P}}{\mathrm{G} i}
$$

em que: $Y i=$ custo da ração por quilograma de peso vivo ganho no $i$-ésimo tratamento; $\mathrm{P} i=$ preço por quilograma da ração utilizada no $i$-ésimo tratamento; $\mathrm{Q} i=$ quantidade de ração consumida no $i$-ésimo tratamento; $\mathrm{G} i=$ ganho de peso do $i$-ésimo tratamento.

Em seguida, foram calculados o Índice de Eficiência Econômica (IEE) e o Índice de Custo (IC), proposto por Gomes et al. (1991).

$$
\mathrm{IEE}=\frac{\mathrm{MC} e}{\mathrm{CT} e i} \times 100 \quad \text { e } \quad \mathrm{IC}=\frac{\mathrm{CT} e i}{\mathrm{Mc} e} \times 100
$$

em que: $\mathrm{MC} e=$ menor custo da ração por quilograma ganho observado entre os tratamentos; CTei = custo do tratamento $i$ considerado.

O consumo diário de ração (CDR), o ganho diário de peso (GDP), a conversão alimentar (CA) e as variáveis econômicas foram submetidos à análise de regressão polinomial. O peso inicial (PI) foi utilizado como covariável para ajuste das variações individuais.

\section{Resultados e Discussão}

\section{Experimento I - Digestibilidade}

Os teores brutos de nutrientes da SGUM (Tabela 2), convertidos para a mesma base de matéria seca do milho seco, conforme a tabela da EMBRAPA (1991), foram inferiores àqueles encontrados na literatura, com exceção do extrato etéreo. Provavelmente, isso ocorreu devido ao fato de o milho utilizado neste trabalho ter sido colhido antes de atingir a maturação fisiológica da planta. A tabela da EMBRAPA (1991) apresenta valores de $8,31 \%$ de $\mathrm{PB} ; 3,86 \%$ de EE; 2,54\% de FB; $4.007 \mathrm{kcal} / \mathrm{kg}$ de EB; $0,01 \%$ de $\mathrm{Ca}$ e $0,23 \%$ de Pt para a silagem de grãos de milho, quando corrigidos para $87,45 \%$ de matéria seca.

Segundo Costa et al. (1999), por ocasião da maturação fisiológica, os grãos apresentam teores máximos de amido, proteínas e óleo. Além disso, as variações nos teores dos nutrientes, que ocorrem entre as silagens, podem ser atribuídas a diversos outros fatores, tais como: potencial genético das sementes para esse atributo, nível de adubação utilizado (especialmente $\mathrm{N}$ ), fertilidade do solo e condições climáticas (Lima et al., 1998).

Os CDEB e CDPB obtidos no presente experimento (Tabela 3) são inferiores àqueles encontrados nas tabelas da EMBRAPA (1991) para a silagem de grãos de milho (95,20 e 95,82\%, respectivamente). Por outro lado, os CDEB, CMEB e CDPB estão próximos daqueles apresentados por Lima et al. (1998), que, trabalhando com duas SGUM de duas 
propriedades diferentes, produzidas sob as mesmas recomendações técnicas, obtiveram 90,76 e $91,01 \%$ para CDEB; 87,62 e 88,08\% para CMEB, e 83,01 e $85,68 \%$ para CDPB.

Quando se comparam estes coeficientes com os CDEB, CMEB e CDPB calculados a partir dos dados apresentados nas tabelas da EMBRAPA (1991) e de Rostagno et al. (2000) para o milho seco, verifica-se que o método de estocagem, sob a forma de silagem de grãos úmidos, melhora a disponibilidade desses nutrientes do milho. O mesmo fato já havia sido relatado por Holmes et al. (1973) e Lima et al. (1998) e, em parte, por Hale et al. (1978) e Asche et al. (1986).

Tabela 2 - Composição química e energética, valor de $\mathrm{pH}$ e diâmetro geométrico médio (DGM) das partículas da silagem de grãos úmidos de milho (SGUM) ${ }^{1}$, na matéria natural e em $87,45 \%$ de matéria seca

Table 2 - Chemical and energy composition, value of $\mathrm{pH}$ and medium geometric diameter (MGD) of particles of high moisture corn silage (HMCS) ${ }^{1}$, as fed basis and $87.45 \%$ of dry matter basis

\begin{tabular}{|c|c|c|}
\hline $\begin{array}{l}\text { Parâmetros } \\
\text { Parameters }\end{array}$ & $\begin{array}{r}\text { SGUM }^{2} \\
H M C S\end{array}$ & $\begin{array}{r}\mathrm{SGUM}^{3} \\
H M C S\end{array}$ \\
\hline Matéria seca, \% & 60,18 & 87,45 \\
\hline Dry matter, \% & & \\
\hline Proteína bruta, $\%$ & 4,29 & 6,23 \\
\hline Crude protein, $\%$ & & \\
\hline $\begin{array}{l}\text { Amido, } \% \\
\text { Starch, } \%\end{array}$ & 42,35 & 61,54 \\
\hline $\begin{array}{l}\text { Extrato etéreo, } \% \\
\text { Ether } \text { extract, } \%\end{array}$ & 2,81 & 4,08 \\
\hline $\begin{array}{l}\text { Fibra bruta, } \% \\
\text { Crude fiber, } \%\end{array}$ & 1,40 & 2,03 \\
\hline $\begin{array}{l}\text { Cinzas, } \% \\
\text { Ash, \% }\end{array}$ & 0,70 & 1,02 \\
\hline $\begin{array}{l}\text { Cálcio, \% } \\
\text { Calcium, \% }\end{array}$ & 0,01 & 0,01 \\
\hline $\begin{array}{l}\text { Fósforo total, } \% \\
\text { Phosphorus, } \%\end{array}$ & 0,14 & 0,20 \\
\hline $\begin{array}{l}\text { Energia bruta, } \mathrm{kcal} / \mathrm{kg} \\
\text { Gross energy, } \mathrm{kcal} / \mathrm{kg}\end{array}$ & 2.628 & 3.819 \\
\hline $\mathrm{pH}$ & 3,80 & - \\
\hline $\begin{array}{l}\text { Diâmetro geométrico médio, } \mu \mathrm{m} \\
\text { Medium geometric diameter, } \mu \mathrm{m}\end{array}$ & 1.501 & - \\
\hline
\end{tabular}

1 Análises realizadas no LANA-DZO/UEM.

2 Valores na matéria natural.

3 Valores convertidos para $87,45 \%$ de MS, conforme os dados apresentados pela tabela da EMBRAPA (1991), para o milho seco (grão).

1 Analyses were performed at LANA-DZO/UEM.

2 Values on natural matter basis.

3 Values converted for $87.45 \%$ of dry matter basis, according to data of EMBRAPA (1991) table, for dry yellow corn (grain).
Os valores de digestibilidade total do amido assemelham-se aos obtidos por Holmes et al. (1973). Os autores relatam que a concentração de amido nas fezes representou menos de $0,2 \%$ do amido ingerido, assumindo, assim, uma digestão completa do amido em ambas as dietas contendo milho seco ou milho úmido. Porém, verificaram que em dietas à base de milho preservado com ácidos orgânicos, a quantidade de amido que passou para o ceco foi cerca de três vezes menor, em comparação à dieta com milho seco. Além disso, mostraram que a estocagem do milho com ácidos orgânicos causou hidrólise do amido, aumentando em até dez vezes a quantidade de glicose livre no alimento em relação ao milho seco.

O CDMS foi menor que os coeficientes de 88,42 e $89,05 \%$ obtidos por Lima et al. (1998), que trabalharam com animais de peso vivo inicial superior $(54,66 \mathrm{~kg})$ e silagens de diâmetro geométrico médio (DGM) inferior (1.236 e $954 \mathrm{~mm}$ ) ao deste trabalho. A menor digestibilidade da matéria seca talvez possa estar relacionada ao maior DGM das partículas de milho da silagem, resultando em maiores partículas de pericarpo, o qual é muito resistente à digestão enzimática no intestino delgado (Jobim et al., 2001). Asche et al. (1986) encontraram menor digestibilidade

Tabela 3 - Coeficientes de digestibilidade aparente da
matéria seca (CDMS), da proteína bruta
(CDPB), do amido (CDAM) e da energia bruta
(CDEB) e coeficiente de metabolização da
energia bruta (CMEB) da silagem de grãos
úmidos de milho (SGUM)
Coefficients of apparent digestibility of dry matter
(DMDC), crude protein (CPDC), starch (SDC) and
gross energy (GEDC) and coefficient of
metabolization of gross energy (GEMC) of high
moisture corn silage (HMCS)

${ }^{1}$ Erro-padrão.

1 Standard error. 
da matéria seca para dietas contendo SGUM em comparação a dietas contendo milho seco para suínos em crescimento.

Hale et al. (1978) obtiveram valores de digestibilidade aparente da fibra bruta numericamente inferiores para dieta com milho úmido ensilado e dieta com milho tratado com ácido propiônico, em relação àquelas com milho seco, o que também pode ajudar a explicar o menor CDMS determinado neste experimento.

O bom valor nutricional da SGUM verificado neste trabalho pode ser explicado, em parte, pelo seu menor valor de $\mathrm{pH}$, pois, segundo Rooney \& Pflugfelder (1986), ácidos ou álcalis diluídos podem promover a gelatinização do amido, sem necessitar de alta temperatura. Os ácidos orgânicos produzidos pelos processos fermentativos, durante o período de armazenamento no silo, podem causar rupturas na matriz protéica que recobre os grânulos de amido, bem como na estrutura desses grânulos, com perda da estrutura cristalina, favorecendo a digestão e absorção do amido, como foi observado por Lopes (2000).

Segundo Holmes et al. (1974), o aumento da acidez da dieta causa atraso no esvaziamento estomacal, dessa forma, é possível que enzimas digestivas, assim como a amilase salivar (Holmes et al., 1974), pepsina e lipase gástrica (Solomon, 1994), possam agir por maior tempo. Além disso, provavelmente, a ação das enzimas digestivas seja mais eficiente nas partículas úmidas de milho (Holmes et al., 1973).

$\mathrm{O}$ aumento da digestão estomacal pode propiciar maior intensidade de estimulação da secreção exócrina do pâncreas, elevando os subprodutos da digestão no quimo, como peptídeos, ácidos graxos e monoacilgliceróis, que são importantes estimulantes luminais dessa secreção no início do intestino delgado (Solomon, 1994).

Holmes et al. (1973) constataram maiores coeficientes de digestibilidade ileal e total da matéria seca, energia e proteína para as dietas contendo milho úmido tratado com ácidos orgânicos ou SGUM, cujo pH variava entre 4,77 e 5,16, em comparação à dieta com milho seco $(\mathrm{pH}=5,35)$. Como conseqüência, menor quantidade de nutrientes (amido e compostos nitrogenados) foi fermentada no intestino grosso, o qual é menos eficiente em prover aminoácidos e energia do substrato para o animal.

Convertendo para $87,45 \%$ de MS, observou-se que os teores de MSD, PD, ED e EM do alimento avaliado (Tabela 4) foram menores que os respecti- vos teores de 77,32 e 77,87\%; 6,16 e 7,32\%; 3.559 e $3.606 \mathrm{kcal} / \mathrm{kg} ; 3.436$ e $3.490 \mathrm{kcal} / \mathrm{kg}$, encontrados por Lima et al. (1998), quando avaliaram duas SGUM diferentes. Também se apresentaram inferiores em relação aos teores de PD, ED e EM da silagem de grãos de milho da tabela da EMBRAPA (1991), cujos resultados, provavelmente, tenham sido obtidos com animais mais velhos.

Ao confrontar os resultados aqui obtidos com os das tabelas da EMBRAPA (1991) e de Rostagno et al. (2000) para o milho seco, observa-se que o teor de PD encontrado é menor $(3,77 \%$ versus a 7,51 e $7,14 \%$, respectivamente). Entretanto, o valor de ED se apresenta bastante próximo $(3.471 \mathrm{kcal} / \mathrm{kg}$ versus 3.460 e $3.490 \mathrm{kcal} / \mathrm{kg}$, respectivamente), e o teor de EM superior $(3.381 \mathrm{kcal} / \mathrm{kg}$ versus $3.293 \mathrm{e}$ $3.331 \mathrm{kcal} / \mathrm{kg}$, respectivamente).

\section{Experimento II - Desempenho}

O aumento dos níveis de substituição do milho seco por SGUM nas rações (Tabela 5) provocou redução linear $(\mathrm{P}<0,05)$ no consumo diário de ração (CDR), no primeiro período analisado, de 0 a 14 dias $\left(\hat{Y}=0,65218-0,00082 X, R^{2}=0,84\right)$, porém não alterou o CDR nos períodos de 14 a 28 dias e total

Tabela 4 - Teores de matéria seca digestível (MSD), proteína digestível (PD), amido digestível (AD), energia digestível (ED) e energia metabolizável (EM) da SGUM, na matéria natural e em $87,45 \%$ de matéria seca

Table 4 - Contents of digestible dry matter (DDM), digestible protein $(D P)$, digestible starch (DS), digestible energy (DE) and metabolizable energy (ME) of high moisture corn silage $(H M C S)^{1}$, in natural matter basis and in $87.45 \%$ of dry matter basis

\begin{tabular}{lcc}
\hline $\begin{array}{l}\text { Nutrientes } \\
\text { Nutients }\end{array}$ & $\begin{array}{c}\text { SGUM } \\
\text { HMCS }\end{array}$ & $\begin{array}{c}\text { SGUM }^{2} \\
\text { HMCS }\end{array}$ \\
\hline $\begin{array}{l}\text { MSD } \% \\
D D M, \%\end{array}$ & 48,70 & 70,76 \\
$\mathrm{PD}, \%$ & & \\
$D P, \%$ & 3,77 & 5,48 \\
$\mathrm{AD}, \%$ & & \\
$D S, \%$ & 61,54 \\
$\mathrm{ED}, \mathrm{kcal} / \mathrm{kg}$ & 2,35 & 3.471 \\
$D E, \mathrm{kcal} / \mathrm{kg}$ & 2.389 & \\
$\mathrm{EM}, \mathrm{kcal} / \mathrm{kg}$ & 2.327 & 3.381 \\
$M E, \mathrm{kcal} / \mathrm{kg}$ & &
\end{tabular}

${ }^{1}$ Valores na matéria natural.

2 Valores convertidos para $87,45 \%$ de matéria seca (MS) conforme os dados apresentados pela tabela da EMBRAPA (1991), para o milho seco (grão).

1 Values on natural matter basis.

2 Values converted for $87.45 \%$ of dry matter basis, according to data of EMBRAPA (1991) table, for dry yellow corn (grain). 
(0 a 28 dias). Lopes et al. (1999a), trabalhando com substituição, na base da matéria seca, de todo o milho da ração por SGUM, não observaram diferença no consumo na fase de creche, entretanto, Lopes et al. (1999b) verificaram menor consumo de ração dos suínos nas fases de crescimento e terminação.

Engelke et al. (1984) constataram maior consumo de ração nas fases de crescimento e terminação, quando o milho da dieta estava sob a forma de silagem de grãos úmidos, comparado com ração à base de milho seco.

Dados de experimentos, conduzidos por Hale et al. (1978), indicaram que ao serem submetidos à livre escolha, os suínos preferiram igualmente dietas con- tendo milho seco ou milho úmido estocado sob atmosfera modificada, quando comparadas com dietas à base de milho tratado com ácido propiônico. Entretanto, quando as duas primeiras dietas foram retiradas, o consumo de ração contendo milho tratado com ácido propiônico foi similar a outras baias com animais sob dieta à base de milho seco. Tais respostas sugerem que variações no consumo, provavelmente, não se devam à palatabilidade das rações contendo SGUM.

Não houve efeito $(\mathrm{P}>0,05)$ dos níveis de substituição do milho seco por SGUM sobre o GPD em qualquer dos períodos analisados. Respotas semelhantes foram obtidas por Engelke et al. (1984) e Lopes et al. (1999b). Com suínos em crescimento e

Tabela 5 - Consumo diário de ração (CDR), ganho diário de peso (GDP) e conversão alimentar (CA) de suínos em fase de creche, alimentados com rações contendo níveis crescentes de substituição do milho seco por SGUM nos períodos experimentais de 0 a 14 , de 14 a 28 e de 0 a 28 dias

Table 5 - Daily feed intake (DFI), daily weight gain (DWG) and feed:gain ratio (F/G) of piglets fed diets with increasing dry corn substitution of HMCS levels in the experimental periods from $0-14,14-28$ and $0-28$ days

\begin{tabular}{|c|c|c|c|c|c|c|}
\hline \multirow[b]{2}{*}{$\begin{array}{l}\text { Variáveis } \\
\text { Variables }\end{array}$} & \multicolumn{4}{|c|}{$\begin{array}{l}\text { Níveis de substituição do milho seco por SGUM, \% } \\
\text { Substitution levels of dry yellow corn for HMCS, \% }\end{array}$} & \multirow[b]{2}{*}{$\mathrm{CV}^{1}, \%$} & \multirow[b]{2}{*}{$\begin{array}{l}\text { Efeito } \\
\text { Effect }\end{array}$} \\
\hline & 0 & 33 & 66 & 100 & & \\
\hline \multicolumn{7}{|c|}{$\begin{array}{l}0 \text { a } 14 \text { dias } \\
0-14 \text { days }\end{array}$} \\
\hline $\begin{array}{l}\mathrm{CDR}, \mathrm{kg} / \mathrm{dia} \\
D F I, \mathrm{~kg} / \mathrm{day}\end{array}$ & 0,647 & 0,610 & 0,551 & 0,567 & 11,22 & Linear $^{2}$ \\
\hline $\begin{array}{l}\text { GDP, } \mathrm{kg} / \mathrm{dia} \\
D W G, \mathrm{~kg} / \text { day }\end{array}$ & 0,403 & 0,418 & 0,359 & 0,403 & 16,58 & $\mathrm{NS}^{3}$ \\
\hline $\begin{array}{l}\mathrm{CA} \\
F / G \\
\end{array}$ & 1,616 & 1,527 & 1,547 & 1,408 & 9,26 & Linear $^{4}$ \\
\hline \multicolumn{7}{|c|}{$\begin{array}{c}14 \text { a } 28 \text { dias } \\
14-28 \text { days }\end{array}$} \\
\hline $\begin{array}{l}\mathrm{CDR}, \mathrm{kg} / \mathrm{dia} \\
D F I, \mathrm{~kg} / \mathrm{day}\end{array}$ & 1,258 & 1,192 & 1,227 & 1,229 & 11,43 & NS \\
\hline $\begin{array}{l}\mathrm{GDP}, \mathrm{kg} / \mathrm{dia} \\
D W G, \mathrm{~kg} / \text { day }\end{array}$ & 0,715 & 0,681 & 0,716 & 0,727 & 10,25 & NS \\
\hline $\begin{array}{l}\text { CA } \\
F / G \\
\end{array}$ & 1,751 & 1,743 & 1,711 & 1,693 & 5,11 & NS \\
\hline \multicolumn{7}{|c|}{$\begin{array}{l}0 \text { a } 28 \text { dias } \\
0-28 \text { days }\end{array}$} \\
\hline $\begin{array}{l}\mathrm{CDR}, \mathrm{kg} / \mathrm{dia} \\
D F I, \mathrm{~kg} / \mathrm{day}\end{array}$ & 0,953 & 0,901 & 0,891 & 0,898 & 10,20 & NS \\
\hline $\begin{array}{l}\text { GDP }, \mathrm{kg} / \mathrm{dia} \\
D W G, \mathrm{~kg} / \text { day }\end{array}$ & 0,559 & 0,550 & 0,538 & 0,565 & 10,42 & NS \\
\hline $\begin{array}{l}\mathrm{CA} \\
F / G\end{array}$ & 1,699 & 1,653 & 1,656 & 1,589 & 4,59 & Linear $^{5}$ \\
\hline
\end{tabular}

${ }^{1}$ Coeficiente de variação; $2 \hat{Y}=0,65218-0,00082 X\left(R^{2}=0,84\right) ;{ }^{3}$ Não significativo $(P>0,05)$;

$4 \hat{\mathrm{Y}}=1,61634-0,00185 \mathrm{X}\left(\mathrm{R}^{2}=0,97\right) ; 5 \hat{\mathrm{Y}}=1,69194-0,00100 \mathrm{X}\left(\mathrm{R}^{2}=0,97\right)$.

${ }^{1}$ Coefficient of variation; ${ }^{2} \hat{Y}=.65218-.00082 X\left(R^{2}=.84\right) ;{ }^{3}$ Not significant $(P>.05) ;{ }^{4} \hat{Y}=1.61634-.00185 X\left(R^{2}=.97\right)$.

$5 \hat{\mathrm{Y}}=1.69194-.00100 X\left(R^{2}=.97\right)$. 
terminação e em fase de creche, respectivamente, Duduk (1988) e Lopes et al. (1999a) constataram maior ganho de peso, ao serem alimentados com rações contendo SGUM, em comparação àqueles submetidos a dietas à base de milho seco.

Foram observadas melhoras lineares $(\mathrm{P}<0,05)$, na CA no primeiro período experimental $(\hat{\mathrm{Y}}=1,61634$ - 0,00185X; $\left.\mathrm{R}^{2}=0,97\right)$ e no período total $(\hat{\mathrm{Y}}=1,69194$ - 0,00100X; $\left.R^{2}=0,97\right)$, com aumento dos níveis de substituição do milho seco por SGUM. Duduk (1988) e Lopes et al. (1999a,b) também verificaram melhora na CA de suínos alimentados com rações contendo SGUM. Por outro lado, Engelke et al. (1984) não encontraram diferenças na CA para animais nas fases de crescimento e terminação.

De acordo com Jongbloed et al. (2000), o melhor desempenho animal, assim como a digestibilidade da matéria seca, matéria orgânica, cinzas, cálcio e fósforo, é devido à presença dos ácidos orgânicos que diminuem o $\mathrm{pH}$ do alimento no trato gastrintestinal, resultando em maior dissociação dos compostos minerais da dieta, que proporciona a formação de complexos minerais quelatados, melhora a sanidade do intestino dos animais e reduz a taxa de esvaziamento gástrico.

A redução do $\mathrm{pH}$ observada nas rações, em função dos níveis crescentes de inclusão de SGUM, pode ter colaborado para a melhoria da CA dos leitões, uma vez que todas as dietas continham o mesmo teor energético. De acordo com Holmes et al. (1974), o aumento da acidez total da dieta de suínos, provocada pela inclusão de milho úmido preservado com ácidos orgânicos, determinou a maior retenção estomacal e fluxo mais uniforme da digestão para o intestino delgado no intervalo das refeições, favorecendo o processo de digestão.

Verificou-se que os valores de DGM das partículas das rações experimentais aumentaram em função dos níveis crescentes de substituição do milho seco por SGUM.

O aumento do DGM das partículas, em função dos níveis de substituição, não afetou o ganho de peso dos animais. Ao contrário de alguns resultados da literatura, houve melhora na conversão alimentar à medida que a inclusão de silagem aumentou. Os resultados sugerem que o baixo $\mathrm{pH}$ e o maior valor de DGM das partículas das rações contendo SGUM podem elevar a retenção estomacal, o que ajuda a explicar, em parte, a diminuição no consumo das rações contendo SGUM no primeiro período.
Clements et al. (1975), trabalhando com diversos tamanhos de partículas em rações de leitões, verificaram tendência em aumentar o tempo de retenção do alimento no estômago, quando o tamanho das partículas aumentava. Entretanto, segundo Zanotto et al. (1995), a digestibilidade e o desempenho dos suínos melhoram com a diminuição do DGM das partículas do milho, sendo que os melhores resultados parecem ser produzidos quando o DGM situa-se entre $500 \mathrm{e}$ $650 \mathrm{~mm}$. Contudo, não foi observado efeito depressor ao desempenho dos animais, pelo contrário, houve melhora na $\mathrm{CA}$, à medida que o DGM das rações experimentais aumentou.

Considerando o custo da SGUM (Tabela 6), de $\mathrm{R} \$ 7,80$ a saca $(60 \mathrm{~kg})$ ensilada e o preço do milho grão seco, de $\mathrm{R} \$ 11,40$ a saca, ajustados para a mesma base de $87,45 \%$ de matéria seca, o custo da ração por quilograma de peso vivo ganho reduziu linearmente $(\mathrm{P}<0,05)(\hat{\mathrm{Y}}=0,66205-0,00076 \mathrm{X}$; $\left.\mathrm{R}^{2}=0,97\right)$, como aumento dos níveis de SGUMnas rações.

$\mathrm{O}$ índice de eficiência econômica (IEE) e o índice de custo (IC) foram melhores nas rações em que a silagem substituiu o milho; dessa forma, a utilização de SGUM foi mais viável economicamente em relação ao uso do milho seco.

Os resultados obtidos apontam que o custo por unidade de peso vivo ganho, dos leitões alimentados com SGUM, foi cerca de $14 \%$ menor em comparação aos animais que receberam milho seco na dieta. Rajic \& Sevkovic (1988), citados por Lopes (2000), verificaram que a conversão alimentar e o custo por unidade de ganho de peso de suínos nas fases de crescimento e terminação foram em torno de $25 \%$ menor nos animais que receberam SGUM comparados com aqueles alimentados com milho seco.

A ausência de taxas e impostos sobre o produto (SGUM), ausência de perdas com transporte, frete e desconto sobre a umidade, menor custo de armazenamento, antecipação do período de colheita e menores perdas por ataques de roedores e insetos (Keplin, 1999) tornam a SGUM uma opção mais econômica em relação ao milho grão seco.

\section{Conclusões}

A silagem de grãos úmidos de milho é uma alternativa viável na alimentação de suínos em fase de creche. O milho seco pode ser totalmente substituído por SGUM nas rações para leitões, com melhora nos índices produtivos e econômicos. 
Tabela 6 - Custo do quilograma de ração, custo de ração por quilograma de peso vivo ganho (CR) dos leitões, índice de eficiência econômica (IEE) e índice de custo (IC)

Table 6 - Diet cost per kilogram, diet cost per kilogram of piglets body weight (DC), economic efficiency rate (EER) and cost rate (CR)

\begin{tabular}{|c|c|c|c|c|c|}
\hline \multirow[b]{2}{*}{$\begin{array}{l}\text { Variáveis } \\
\text { Variables }\end{array}$} & \multicolumn{4}{|c|}{$\begin{array}{l}\text { Níveis de substituição do milho seco por SGUM, \% } \\
\text { Substitution levels of dry yellow corn for HMCS, \% }\end{array}$} & \multirow[b]{2}{*}{$\mathrm{CV}^{1}, \%$} \\
\hline & 0 & 33 & 66 & 100 & \\
\hline $\begin{array}{l}\text { Custo da ração }{ }^{2}, \mathrm{R} \$ / \mathrm{kg} \\
\text { Diet cost, } R \$ / \mathrm{kg}\end{array}$ & 0,389 & 0,381 & 0,373 & 0,365 & - \\
\hline $\begin{array}{l}\mathrm{CR}^{3}, \mathrm{R} \$ / \mathrm{kg} \text { PV ganho } \\
D C^{3}, R \$ / \mathrm{kg} B W \text { gain }\end{array}$ & 0,660 & 0,630 & 0,618 & 0,581 & 4,68 \\
\hline $\begin{array}{l}\text { IEE } \\
\text { EER }\end{array}$ & 88 & 92 & 94 & 100 & - \\
\hline $\begin{array}{l}\mathrm{IC} \\
C R\end{array}$ & 114 & 108 & 106 & 100 & - \\
\hline $\begin{array}{l}1 \text { Coeficiente de variação. } \\
2 \text { Custos baseados em um } \\
3 \text { Custo em ração por kg de } \\
1 \text { Coefficient of variation. } \\
2 \text { Costs based on prices relatic }\end{array}$ & $\begin{array}{l}\text { ho de pre } \\
\text { ho no per } \\
\text { uCS of } 68 \text {. }\end{array}$ & $\begin{array}{l}\text { a SG } \\
\text { ito line } \\
\text { of dry }\end{array}$ & $\begin{array}{l}68,42 \% \\
05), \hat{\mathrm{Y}} \\
\text { ue. }\end{array}$ & $\begin{array}{l}\text { alor }(R \$) \text { do } r \\
205-0,00076\rangle\end{array}$ & $\begin{array}{l}\text { lo seco. } \\
2=0,97)\end{array}$ \\
\hline
\end{tabular}

\section{Literatura Citada}

ASCHE, G.L.; CRENSHAW, J.D.; LEWIS, A.J. et al. Effect of dry, high-moisture and reconstitued normal and high-lysine corn diets and particle size on energy and nitrogen metabolism in growing swine. Journal of Animal Science, v.63, p.131-138, 1986.

BACK, S.P. Aspectos econômicos da silagem de grãos úmidos de milho na alimentação de suínos. In: LAZZARI, F.A., LAZZARI, S.M.N. (Ed.) Silagem de grão úmido de milho. 1.ed. Curitiba: FAPEAGRO, 2001. p.47-60.

BELLAVER, C.; FIALHO, E.T.; PROTAS, J.F.S. et al. Radícula de malte na alimentação de suínos em crescimento e terminação. Pesquisa Agropecuária Brasileira, v.20, n.8, p.969-974, 1985.

CLEMENTS, E.T.; STEVENS, C.E.; SOUTH WORTH, M. Sites of digesta movement in the gastrintestinal tract of swine. Journal of Nutrition, v.105, p.759-766, 1975.

COSTA, C.; ARRIGONI, M.D.B.; SILVEIRA, A.C. et al. Silagem de grãos úmidos. In: SIMPÓSIO SOBRE NUTRIÇÃO DE BOVINOS, 7., 1999, Piracicaba. Anais... Piracicaba: Fundação de Estudos Agrários Luiz de Queiroz, 1999. p.69-88.

DUDUK, V. High moisture corn for fattened pigs. Georgicon for Agriculture, v.1, n.1, p.71-78, 1988.

EMPRESA BRASILEIRA DE PEQUISA E AGROPECUÁRIA - EMBRAPA. Tabela de composição química e valores energéticos de alimentos para suínos e aves. 3.ed. Concórdia: EMBRAPA - CNPSA, 1991. 97p.

ENGELKE, G.L.; JURGENS, M.H.; SPEER, V.C. Performance of growing-finishing swine fed high-moisture or artificially dried corn in complete and free-choice diets. Journal of Animal Science, v.58, n.6, p.1307-1312, 1984.

GOMES, M.F.M.; BARBOSA, H.P.; FIALHO, E.T. et al. Análise econômica da utilização do triguilho para suínos. (S.I.): EMBRAPA - Centro Nacional de Pesquisa de Suínos e Aves, 1991. p.1-2 (Comunicado Técnico, 179).

HALE, O.M.; WILSON, D.M.; JAY, E. Acceptability and digestibility of swine diets containing corn stored under different conditions. Journal of Animal Science, v.47, n.1, p.46-50, 1978.

HOLMES, J.G.; BAYLEY, H.S.; HORNEY, F.D. Digestion and absorption of dry and high-moisture maize diets in the small and large intestine of the pig. British Journal of Nutrition, v.30, n.3, p.401-410, 1973.

HOLMES, J.G.; BAYLEY, H.S.; HORNEY, F.D. Digestion of dry and high-moisture maize diets in stomach of the pig. British Journal of Nutrition, v.32, n.3, p.639-646, 1974.

JOBIM, C.C.; CECATO, U.; CANTO, M.W. Utilização da silagem de grãos de cereais na alimentação animal. In: SIMPÓSIO SOBRE PRODUÇÃO E UTILIZAÇÃO DE FORRAGENS CONSERVADAS, 2001, Maringá. Anais... Maringá: Universidade Estadual de Maringá, 2001. p.319.

JONGBLOED, A.W.; MROZ, Z.; Van Der WEIJ-JONGBLOED, R. et al. The effects of microbial phytase, organic acids and their interaction in diets for growing pigs. Livestock Production Science, v.67, n.1-2, p.113-122, 2000.

KEPLIN, L.A.S. Silagem de grãos úmidos, 1999, <http:// www.correionet.com.br/ fr17/graos.htm. 37K., 01/08/2000.

LIMA, G.J.M.M.; SOUZA, O.W.; BELLAVER, C. et al. 1998. Determinação da composição química e do valor energético de silagem de grãos úmidos de milho para suínos. In: CONGRESSO NACIONAL DE MILHO E SORGO, 22, 1998, Recife. Anais... Recife: ABMS, [1998]. 2 par. CD-ROM. Seção Industrialização e Tecnologia de Alimento.

LOPES, A.B.R.C. Silagem de grãos úmidos em rações de suínos nas fases inicial, de crescimento e terminação. Botucatu: Universidade Estadual Paulista, 2000, 46p. Dissertação (Mestrado em Zootecnia) - Universidade Estadual Paulista, 2000.

LOPES, A.B.R.C.; BERTO, D.A.; COSTA, C. et al. Silagem de grãos úmidos de milho para suínos na fase inicial. In: REUNIÃO ANUAL DA SOCIEDADE BRASILEIRA DE ZOOTECNIA, 36., 1999, Porto Alegre. Anais... São Paulo/Gnosis, [1999a] 17 par. CD-ROM. Nutrição de Não-Ruminantes. NUN-112.

R. Bras. Zootec., v.33, n.1, p.146-156, 2004 
LOPES, A.B.R.C.; BERTO, D.A.; COSTA, C. et al. Silagem de grãos úmidos de milho para suínos nas fases de crescimento e terminação. In: REUNIÃO ANUAL DA SOCIEDADE BRASILEIRA DE ZOOTECNIA, 36., 1999, Porto Alegre. Anais... São Paulo/Gnosis, [1999b] 17 par. CD-ROM. Nutrição de Não-Ruminantes. NUN-114.

MATTERSON, L.D.; POTTER, L.M.; STUTZ, M.W. et al. The metabolizable energy of feed ingredients for chickens. Research Report, v.7, n.1, p.11-14, 1965.

MOREIRA, I.; ROSTAGNO, H.S.; COELHO, D.T. et al. Determinação dos coeficientes de digestibilidade, valores energéticos e índices de controle de qualidade do milho e soja integral processados pelo calor. Revista Brasileira de Zootecnia, v.23, p.916-929, 1994.

NATIONAL RESEARCH COUNCIL - NRC. Nutrients requirements of swine. 20.ed. Washington, D.C.: 1998. $189 \mathrm{p}$.

PARR INSTRUMENTS CO., Moline, ie. Instructions for the 1241 and 1242 adiabatic calorimeters. Moline: 1984. 29p. (Parr Manual, 153)

PEKAS, J.C. Versatible swine laboratory apparatus for physiologic and metabolic studies. Journal of Animal Science, v.27, n.5, p.1303-1309, 1968.

PEREIRA, J.R.A., ROSSI, J.R.P. Manual prático de avaliação nutricional dos alimentos. Piracicaba: Fundação de Estudos Agrários Luiz de Queiroz, 1995. 25p.

PHILLIP, L.E.; FELLNER, V. Effects of bacterial inoculation of high moisture ear corn on its aerobic stability, digestion and utilization for growth by beef steers. Journal of Animal Science, v.70, p.3178-3187, 1992.
ROONEY, L.W.; PFLUGFELDER, R.L. Factors affecting starch digestibility with special emphasis on sorghum and corn. Journal of Animal Science, v.63, p.1607-1623, 1986.

ROSTAGNO, H.S.; ALBINO, L.F.T.; DONZELE, J.L. et al. Tabelas brasileiras para aves e suínos - Composição de alimentos e exigências nutricionais. Viçosa, MG: Universidade Federal de Viçosa, 2000. 141p.

SILVA, D.J. Análise de alimentos (Métodos químicos e biológicos). 2.ed. Viçosa, MG: Universidade Federal de Viçosa, 1990. $165 \mathrm{p}$.

SOLOMON, T.E. Control of exocrine pancreatic secretion. In: JOHNSON, L.R. et al. (Eds.) Physiology of the gastrointestinal tract. 3.ed. New York: Raven Press, 1994. p.1499-1529.

ZANOTTO, D.; MOTICELLI, C.; MAZZUCO, C. Implicações da granulometria de ingredientes de rações sobre a produção de suínos e aves. In: SIMPÓSIO LATINO-AMERICANO DE NUTRIÇÃO DE SUÍNOS E AVES, 1995, Campinas. Anais... Campinas: Colégio Brasileiro de Nutrição Animal, 1995. p.166.

ZANOTTO, L.D.; BELlaVER, C. Método de determinação da granulometria de ingredientes para o uso em rações de suínos e aves. (S.I.): Centro Nacional de Pesquisa de Suínos e Aves/EMBRAPA, 1996. p.15 (Comunicado Técnico, 215).

Recebido em: 08/07/02 Aceito em: 24/06/03 